\title{
The role of monocyte to HDL ratio in predicting clinically significant carotid stenosis in patients with asymptomatic carotid artery disease
}

1. Balıkesir Sevgi Hospital, Department of Cardiology, Balıkesir, Turkey 2. Pamukkale University, Faculty of Medicine, Department of Cardiology, Denizli, Turkey

3. İstanbul Aydın University, Department of Cardiology, İstanbul, Turkey

\section{SUMMARY}

OBJECTIVE: Monocyte count to HDL-C Ratio (MHR) and Fibrinogen to Albumin Ratio (FAR) have recently emerged as markers of inflammation in atherosclerotic diseases. Our goal was to investigate the relationships of MHR and FAR with the severity of carotid artery stenosis (CAS) in patients with asymptomatic carotid artery disease.

METHODS: This retrospective study consisted of 300 patients with asymptomatic CAS. Pre-angiographic MHR, FAR, and high-sensitive $C$-reactive protein (hsCRP) were measured. Carotid angiography was performed in patients with $\geq 50 \%$ stenosis on carotid ultrasonography. Patients were first split into 2 groups based on the degree of CAS and then tertiles $(T)$ of MHR.

RESULTS: 96 patients had clinically insignificant CAS (<50\%) (Group-1), and 204 patients had clinically significant CAS ( $\geq 50 \%)$ (Group-2). Group-2 had higher MHR, FAR, and hsCRP than group-1. Patients in T3 had higher MHR, FAR, and hsCRP than in T1 and T2. MHR, $F A R$, and hsCRP were correlated with each other ( $p<0.001$, for all). MHR, FAR, and hsCRP were independent predictors of significant CAS. MHR better predicted a significant CAS than FAR and hSCRP $(p<0.05)$.

CONCLUSION: Pre-angiographic MHR may be a better predictor than FAR and hSCRP in identifying a clinically significant carotid stenosis in patients with asymptomatic CAS. Patients with asymptomatic CAS and a high level of MHR should be followed-up closely to supervise risk-factor control and intensify treatment.

KEYWORDS: Inflammation. Carotid stenosis. Monocyte to HDL ratio. Fibrinogen to albumin ratio. Angiography.

\section{INTRODUCTION}

Carotid atherosclerotic stenosis is an important risk indicator for the development of cerebro-cardiovascular events. As the severity of carotid stenosis increases, the risk of stroke increases ${ }^{1}$. Inflammation has an important role in the development, advancement, and destabilization of carotid atherosclerosis $^{2,3}$. Atherosclerotic lesions in the carotid arteries have been found to be related to inflammatory markers ${ }^{3,4}$.

Monocytes, one type of inflammatory marker, or

DATE OF SUBMISSION: 21-Jan-2020

DATE OF ACCEPTANCE: 26-Feb-2020

CORRESPONDING AUTHOR: Mustafa Yurtdaş

Balıkesir Sevgi Hospital, Department of Cardiology, Paşaalanı Mahallesi, 10020, Balıkesir, Turkey

Tel: 09026624633 10, Fax: 0902662463370

E-mail: mustafayurtdas21@gmail.com 
their subunits have an independent role in predicting subclinical atherosclerosis and cardiovascular disease ${ }^{5,6}$. High-density lipoprotein-cholesterol (HDLC) has anti-inflammatory and anti-oxidant effects by inhibiting the adhesion of monocytes to the endothelium. Low HDL-C levels lead to the progression of atherosclerosis ${ }^{5,7,8}$. Fibrinogen, a component of the coagulation cascade, has pro-inflammatory effects and has been demonstrated to have an essential role in atherogenesis ${ }^{4}$. Serum albumin, responsible for the vast majority of total osmotic pressure, plays a crucial role in inhibiting platelet activation and aggregation ${ }^{9}$. A low albumin level is associated with the increased viscosity and concentration of free lysophosphatidylcholine, which may give rise to endothelial dysfunction $^{10}$. Monocyte to HDL-C ratio (MHR) and fibrinogen to albumin ratio (FAR) have been reported to be more suitable and efficient as a marker of cardiovascular disease than their individual measurements ${ }^{11,12}$.

In several studies, MHR and FAR have been demonstrated to be related to adverse outcomes in patients with risk factors or cardiovascular disease ${ }^{5,8,11-17}$. MHR and FAR may be used as cost-effective predictors of adverse events. To our knowledge, there has been no research assessing the pre-angiographic value of MHR and FAR to determine the severity of carotid artery stenosis (CAS). The hypothesis of the present research was that the relationship of MHR and FAR with carotid stenosis might help better classify the risk of those patients at a higher risk for carotid events. Therefore, we aimed to investigate MHR and FAR before carotid angiography and determine their relationships with the severity of CAS obtained during carotid angiography in patients with asymptomatic carotid artery disease.

\section{METHODS}

The study design was retrospective. A total of 300 asymptomatic patients with multiple cardiovascular risk factors who presented to cardiology and neurology outpatient clinics were included. Patients had undergone bilateral carotid angiograms due to $\geq 50 \%$ stenosis in at least 1 internal carotid artery on the duplex carotid ultrasonography between January 2018 and May 2019. Subjects with left ventricular hypertrophy, systolic dysfunction (ejection fraction less than 50\%), moderate to severe diastolic dysfunction, moderate to severe valvular disease, arrhythmias, left bundle branch block, heart enlargement or failure, acute coronary syndromes, acute cerebrovascular diseases, connective tissue diseases, thyroid disorders, pulmonary diseases, kidney diseases, recent operation ( $<3$ months), and trauma were excluded. Other systemic disorders such as inflammatory and infectious diseases were also excluded from the trial. All participants gave written informed consent before being enrolled. The study was regulated in compliance with the Declaration of Helsinki. The local ethical committee approved our study.

All blood samples were taken, following $12 \mathrm{~h}$ of fasting, in the morning of the day in which carotid angiography was performed. A complete blood count with automated differential counts and lipid profile was assessed. MHR was calculated as the ratio of the monocyte count to HDL-C. Fibrinogen and serum albumin levels were evaluated. The FAR was measured as the ratio of fibrinogen to albumin. Clinically significant CAS was defined as a stenosis diameter of $\geq 50 \%{ }^{18}$.

Continuous variables were given as means \pm standard deviation (SD), whereas categorical ones were given as percentages (\%). Kolmogorov-Smirnov test was used to test the normal distribution of measurements. When comparing more than 2 groups, ANOVA or the Kruskal Wallis test was used. For comparison of the continuous data between the two groups, an independent t-test or a Mann-Whitney $\mathrm{U}$ test was used according to whether the data had a normal distribution or not, respectively. For categorical data, the $\chi 2$ test was used for further analysis. The Pearson or Spearmen test was used to assess correlations between the variables. In order to identify independent predictors of significant CAS in patients with asymptomatic carotid artery disease, univariate and then multivariate logistic analyses were carried out. To identify the cutoff values of MHR, FAR, and hsCRP in predicting a significant CAS, a receiver operating characteristic (ROC) curve was produced. To compare the AUCs from the ROC curves of these 3 inflammatory parameters, the deLong test was used. A 2-sided p-value of less than $5 \%$ was accepted as statistically significant. SPSS software was used for all analyses (version 22.0; SPSS Inc).

\section{RESULTS}

A total of 300 patients with asymptomatic CAS were included into the study. Patients were split into 2 groups based on the severity (or clinical significance) of CAS obtained during the carotid angiography. 96 
TABLE 1. COMPARISON OF CLINICAL AND LABORATORY DATA ACCORDING TO THE SEVERITY OF CAROTID STENOSIS IN PATIENTS WITH ASYMPTOMATIC CAROTID ARTERY DISEASE.

\begin{tabular}{|c|c|c|c|}
\hline Variables & $\begin{array}{l}\text { (Group-1) } \\
\text { Insignifi- } \\
\text { cant CAS } \\
(<50 \%) \\
(n=96)\end{array}$ & $\begin{array}{l}\text { (Group-2) } \\
\text { Significant } \\
\text { CAS } \\
(\geq 50 \%) \\
(n=204)\end{array}$ & $P$ value \\
\hline \multicolumn{4}{|l|}{ Clinical data } \\
\hline Age, (years) & $70.0 \pm 7.2$ & $72.5 \pm 7.2$ & 0.008 \\
\hline Female gender, n (\%) & $43(44.7)$ & $97(47.5)$ & 0.710 \\
\hline Hypertension, n (\%) & $47(48.9)$ & $116(56.9)$ & 0.216 \\
\hline Hyperlipidemia, n (\%) & $42(43.8)$ & $96(47.1)$ & 0.621 \\
\hline Diabetes mellitus, n (\%) & $24(25.0)$ & $79(38.7)$ & 0.020 \\
\hline Current smoker, n (\%) & $32(33.3)$ & $70(34.3)$ & 0.867 \\
\hline $\mathrm{BMI}, \mathrm{kg} / \mathrm{m}^{2}$ & $26.1 \pm 2.5$ & $26.8 \pm 2.9$ & 0.031 \\
\hline History of CAD & $32(33.3)$ & $94(46.1)$ & 0.045 \\
\hline LVEF (\%) & $62 \pm 5.1$ & $61 \pm 5.5$ & 0.319 \\
\hline Statin, n (\%) & $32(33.3)$ & $89(43.6)$ & 0.102 \\
\hline ACE-I/ARB, n (\%) & $43(44.8)$ & $109(53.4)$ & 0.175 \\
\hline Beta blocker, n (\%) & $41(42.7)$ & $99(48.5)$ & 0.386 \\
\hline \multicolumn{4}{|c|}{ Pre-angiographic laboratory data } \\
\hline Serum creatinine (mg/dL) & $0.90 \pm 0.15$ & $0.91 \pm 0.16$ & 0.723 \\
\hline hsCRP (mg/dL) & $2.68 \pm 1.95$ & $3.42 \pm 1.76$ & 0.002 \\
\hline Fibrinogen (mg/dL) & $289 \pm 68$ & $312 \pm 63$ & 0.004 \\
\hline Albumin (mg/dL) & $3.94 \pm 0.48$ & $3.76 \pm 0.52$ & 0.006 \\
\hline $\begin{array}{l}\text { Fibrinogen to albumin } \\
\text { ratio }\end{array}$ & $74 \pm 19$ & $84 \pm 21$ & $<0.001$ \\
\hline $\mathrm{LDL}-\mathrm{C}(\mathrm{mg} / \mathrm{dL})$ & $126 \pm 30$ & $127 \pm 27$ & 0.698 \\
\hline $\mathrm{HDL}-\mathrm{C}(\mathrm{mg} / \mathrm{dL})$ & $41 \pm 12$ & $34 \pm 8$ & $<0.001$ \\
\hline Hemoglobin (g/dL) & $13.6 \pm 1.5$ & $13.7 \pm 1.6$ & 0.543 \\
\hline WBC $\left(\times 10^{3} / \mathrm{mm}^{3}\right)$ & $6.9 \pm 1.3$ & $7.2 \pm 1.7$ & 0.081 \\
\hline Platelet $\left(\times 10^{3} / \mathrm{mm}^{3}\right)$ & $242 \pm 97$ & $246 \pm 88$ & 0.691 \\
\hline Monocyte $\left(\times 10^{6} / \mathrm{mm}^{3}\right)$ & $417 \pm 164$ & $495 \pm 143$ & $<0.001$ \\
\hline Monocyte to HDL ratio & $12.1 \pm 8.4$ & $15.7 \pm 6.2$ & $<0.001$ \\
\hline Bilateral CAS, n (\%) & $19(19.8)$ & $64(31.3)$ & 0.039 \\
\hline The degree of CAS, (\%) & $23 \pm 11$ & $70 \pm 14$ & $<0.001$ \\
\hline \multicolumn{4}{|c|}{$\begin{array}{l}\text { ACE-I, angiotensin-converting enzyme inhibitors; } A R B \text {, angiotensin receptor block- } \\
\text { er; BMI, body mass index; CAD, coronary artery disease; CAS, carotid artery stenosis; } \\
\text { hsCRP, high-sensitivity C-reactive protein; HDL-C, high-density lipoprotein-choles- } \\
\text { terol; LVEF, left ventricular ejection fraction; LDL-C, low-density lipoprotein-choles- } \\
\text { terol; WBC, white blood cell. }\end{array}$} \\
\hline
\end{tabular}

patients (32\%) had clinically insignificant CAS (<\%50) (group-1), 204 patients (68\%) had clinically significant CAS ( $\geq 50 \%$ ) (group-2). Table 1 shows the comparison of clinical and laboratory data of the two groups. Group-2 patients had older age, a greater body mass index, higher rates of history of coronary artery disease (CAD), diabetes mellitus, and 2-sided carotid disease, lower albumin and HDL-C, greater hsCRP, monocyte, and fibrinogen, and greater MHR and FAR than group-1 patients. Then, the study population was split into tertiles (T) based on pre-angiographic MHR
(T1:<10.33; T2:10.33-16.60; T3:>16.60). Table 2 shows the comparison of clinical and laboratory parameters of patients by tertiles (T) of MHR. Patients in T3 showed higher hsCRP, fibrinogen, monocyte counts, and lower HDL-C, and also higher FAR than in T1 and T2. Patients in T3 and T2 also showed a greater degree of CAS than in T1.

According to univariate analysis, age, diabetes mellitus, BMI, history of CAD, the presence of 2-sided carotid disease, MHR, FAR, and hsCRP were significantly associated with significant CAS. Multivariate analysis showed that diabetes mellitus, BMI, MHR, FAR, and hsCRP were independent predictors of significant CAS.

In the correlation analysis, MHR, FAR and hsCRP were significantly correlated to each other (MHRhsCRP: $r=0.706, p<0.001$; FAR-hsCRP: $r=0.622$, $\mathrm{p}<0.001$; MHR-FAR: 0.637, $\mathrm{p}<0.001)$. While the degree of CAS was associated with MHR ( $\mathrm{r}=0.195, \mathrm{p}=0.001)$ and FAR ( $r=0.166, p=0.004)$, it was not associated with hsCRP ( $\mathrm{r}=0.093, \mathrm{p}=0.106)$.

Finally, the ROC curve analysis showed the cutoff value of $\geq 11$ for MHR with a sensitivity of $75 \%$ and a specificity of 70\% (AUC: 0.732; CI, 0.660-0.804;

FIGURE 1. RECEIVER OPERATING CHARACTERISTIC (ROC) CURVES OF THE PRE-ANGIOGRAPHIC MONOCYTE TO HDL RATIO (MHR), FIBRINOGEN TO ALBUMIN RATIO (FAR,) AND HIGH-SENSITIVE C-REACTIVE PROTEIN (HSCRP) FOR PREDICTING CLINICALLY SIGNIFICANT CAROTID STENOSIS IN PATIENTS WITH ASYMPTOMATIC CAROTID ARTERY DISEASE. (AUC, AREA UNDER THE CURVE; CI, CONFIDENCE INTERVAL)

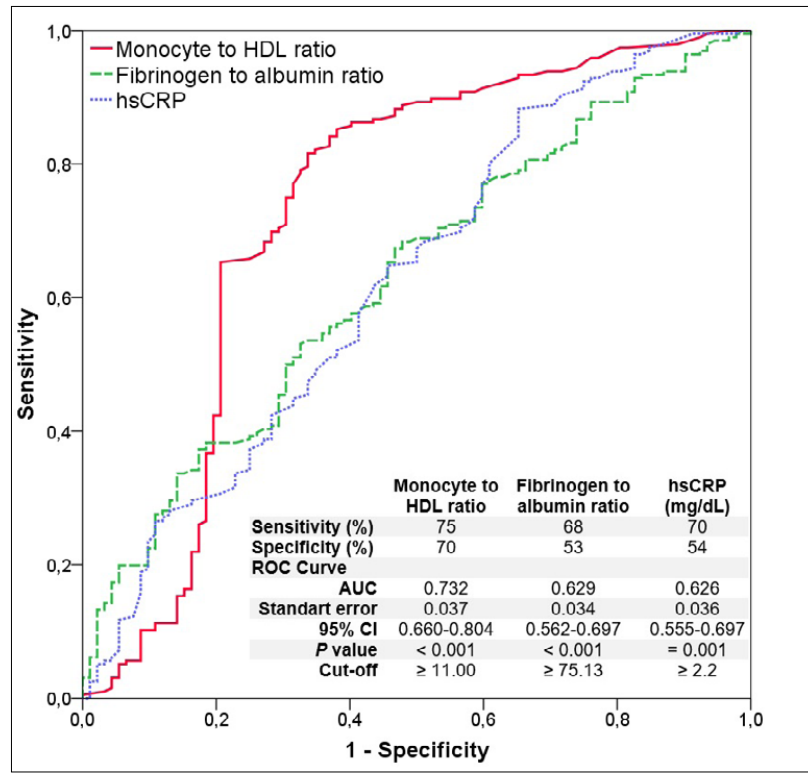


TABLE 2. COMPARISON OF CLINICAL AND LABORATORY DATA BYTERTILES OF MHR IN PATIENTS WITH ASYMPTOMATIC CAROTID ARTERY DISEASE.

\begin{tabular}{|c|c|c|c|c|}
\hline Variables & $\begin{array}{l}\text { Tertile } 1 \\
(<10.33) \\
(n=100)\end{array}$ & $\begin{array}{l}\text { Tertile } 2 \\
(10.33-16.60) \\
(n=100)\end{array}$ & $\begin{array}{l}\text { Tertile } 3(>16.60) \\
(n=100)\end{array}$ & P value \\
\hline \multicolumn{5}{|l|}{ Clinical data } \\
\hline Age (years) & $71.1 \pm 7.2$ & $71.4 \pm 7.1$ & $72.8 \pm 7.5$ & 0.219 \\
\hline Female gender, $(n, \%)$ & $42(42)$ & $47(47)$ & $51(51)$ & 0.443 \\
\hline Hypertension, (n, \%) & $49(49)$ & $59(59)$ & $55(55)$ & 0.361 \\
\hline Hyperlipidemia, (n, \%) & $41(41)$ & $46(46)$ & $51(51)$ & 0.366 \\
\hline Current smoker, (n, \%) & $31(31)$ & $38(38)$ & $33(33)$ & 0.560 \\
\hline $\mathrm{BMI}(\mathrm{kg} / \mathrm{m} 2)$ & $26.4 \pm 2.5$ & $26.5 \pm 2.9$ & $26.8 \pm 2.9$ & 0.586 \\
\hline History of CAD, (n, \%) & $36(36)$ & $40(40)$ & $52(52)$ & 0.059 \\
\hline LVEF (\%) & $60.9 \pm 5.1$ & $61.1 \pm 5.3$ & $62.1 \pm 5.6$ & 0.240 \\
\hline Statin, (n, \%) & $40(40)$ & $39(39)$ & $42(42)$ & 0.903 \\
\hline ACE-I/ARB, (n, \%) & $44(44)$ & $50(50)$ & $58(58)$ & 0.118 \\
\hline Beta blocker, (n, \%) & $44(44)$ & $47(47)$ & $49(49)$ & 0.760 \\
\hline \multicolumn{5}{|c|}{ Pre-angiographic laboratory data } \\
\hline Serum creatinine $(\mathrm{mg} / \mathrm{dL})$ & $0.90 \pm 0.15$ & $0.91 \pm 0.16$ & $0.90 \pm 0.16$ & 0.907 \\
\hline hsCRP (mg/L) & $2.45 \pm 1.7$ & $3.22 \pm 1.9^{*}$ & $3.85 \pm 1.7^{\star \star}$ & $<0.001$ \\
\hline Fibrinogen (mg/dL) & $283 \pm 63$ & $305 \pm 59^{*}$ & $326 \pm 67^{\star *}$ & $<0.001$ \\
\hline Albumin (mg/dL) & $3.87 \pm 0.52$ & $3.82 \pm 0.42$ & $3.79 \pm 0.58$ & 0.522 \\
\hline Fibrinogen to albumin ratio & $74 \pm 19$ & $81 \pm 18^{*}$ & $88 \pm 23^{\star \star}$ & $<0.001$ \\
\hline $\mathrm{LDL}-\mathrm{C}(\mathrm{mg} / \mathrm{dL})$ & $126 \pm 30$ & $127 \pm 27$ & $127 \pm 26$ & 0.977 \\
\hline $\mathrm{HDL}-\mathrm{C}(\mathrm{mg} / \mathrm{dL})$ & $46 \pm 9$ & $34 \pm 5^{*}$ & $29 \pm 5^{\star *}$ & $<0.001$ \\
\hline Hemoglobin (g/dL) & $13.8 \pm 1.7$ & $13.7 \pm 1.4$ & $13.6 \pm 1.6$ & 0.816 \\
\hline WBC (x103/mm3) & $6.9 \pm 1.6$ & $7.1 \pm 1.5$ & $7.2 \pm 1.7$ & 0.346 \\
\hline Platelet (x103/mm3) & $250 \pm 102$ & $253 \pm 88$ & $259 \pm 84$ & 0.787 \\
\hline Monocyte (x106/mm3) & $314 \pm 31$ & $447 \pm 88^{*}$ & $647 \pm 80^{* *}$ & $<0.001$ \\
\hline Monocyte to HDL ratio & $7.2 \pm 1.7$ & $13.3 \pm 1.9^{*}$ & $23 \pm 4.3^{\star \star}$ & $<0.001$ \\
\hline Bilateral CAS, n (\%) & $26(26)$ & $23(23)$ & $34(34)$ & 0.199 \\
\hline The degree of CAS, (\%) & $45 \pm 24$ & $59 \pm 26^{\star}$ & $62 \pm 211 \S$ & $<0.05$ \\
\hline
\end{tabular}

$\mathrm{p}<0.001$ ), and the cutoff value of $\geq 75$ for FAR with a sensitivity of $68 \%$ and a specificity of $53 \%$ (AUC: 0.629; CI, 0.562-0.697; $\mathrm{p}<0.001)$, and the cut-off value $\geq 2.2$ for hsCRP with a sensitivity of $70 \%$ and a specificity of 54\% (AUC: 0.626; CI, 0.555-0.697; $\mathrm{p}<0.001)$ to predict significant CAS. The predictive values of pre-angiographic MHR, FAR, and hsCRP were compared by their AUCs. Pre-angiographic MHR better predicted a significant CAS than FAR and hsCRP $(\mathrm{p}<0.05)$ (Figure 1).

\section{DISCUSSION}

In our study, we demonstrated that pre-angiographic levels of MHR, FAR, and hsCRP in patients with significant CAS were higher than in those with insignificant CAS. Pre-angiographic MHR was found to be a better predictor than FAR and hsCRP in determining the presence of a clinically significant CAS in patients with asymptomatic carotid artery disease.

Monocytes act as a crucial source of pre-inflammatory species during atherosclerosis, and they change into foam cells to release pro-inflammatory and pro-oxidant cytokines, resulting in the collection of more monocytes and building up of cholesterol ester-loaded plaque at the inflammation area ${ }^{5}$. Several studies have shown that greater monocyte counts are a crucial indicator of adverse events in atherosclerotic diseases such as CAD and ischemic stroke ${ }^{5,6}$. HDL-C has anti-inflammatory and anti-oxidant effects by hindering LDL-C oxidation and monocytes entering into the vascular wall, resulting in endothelial or 
vascular protection from inflammation and oxidative stress $^{5,7}$. Ultimately, while monocytes play an active role through their pro-oxidant and pro-inflammatory effects, HDL-C serves as a neutralizer by suppressing inflammatory markers such as monocytes in atherosclerotic events. For this reason, the integration of monocytes and HDL-C into MHR produces an organized formula to assess atherosclerosis by examining the association between inflammation and dyslipidemia $^{5,8}$. Investigations have shown the usability of MHR to predict cardiovascular outcomes of metabolic syndrome and several atherosclerotic diseases, such as in-stent restenosis, and CAD ${ }^{14-16}$. Recently, Cetin et al. ${ }^{16}$ found that MHR was an independent predictor of the severity of CAD and had a significantly positive correlation with CRP levels. In our study, MHR was a better predictor than FAR and hsCRP in determining significant CAS and had a significant association with FAR and hsCRP, indicating that inflammation could play a pivotal role in the pathogenesis of carotid atherosclerosis. In line with our findings, Wang et al. ${ }^{8}$ evaluated the association between MHR and ischemic stroke and found a linear relation of MHR with ischemic stroke in a large cohort.

Patients with CAS have high fibrinogen levels ${ }^{3,4}$. Little is known about the relationship between albumin level and CAS, and data from those studies have been inconsistent ${ }^{19,20}$. Because fibrinogen and albumin a positive and negative correlations with the inflammatory reaction, respectively, their proportion may be associated with inflammation. Therefore, fibrinogen and albumin levels have been recommended to be assessed together, when their effects on cardiovascular disease are explored ${ }^{11,12}$. FAR was found to be significantly higher in patients with cardiovascular events than in those without any cardiovascular event ${ }^{11}$. In a study by Karahan et al. ${ }^{17}$ FAR was reported to be a highly specific indicator for predicting the severity of CAD in ST-elevation myocardial infarction. Moreover, He et al. ${ }^{12}$ have recently shown that FAR might serve as a prognostic marker in non-ST-elevation myocardial infarction. In line with these data, we found that FAR was one of the indicators in predicting significant CAS in our study. Additionally, we observed that FAR was associated with other inflammatory parameters such as hsCRP and MHR. Another finding was that FAR and MHR were moderately associated with the degree of CAS. However, we could not find any relationship between hsCRP and the degree of CAS. To our knowledge, there is no information in the literature about the association of MHR and FAR with the degree of stenosis. Puz et al. ${ }^{2}$ showed that higher hsCRP values were able to predict the presence of carotid artery plaque, but they were not associated with the degree of carotid stenosis, strongly supporting our data.

Our study has several limitations. First, we could not observe time-dependent changes in MHR and FAR levels or the degree of CAS because of the cross-sectional study design. Second, single computations may not entirely show the true trend of the analyzed variables. Therefore, we could not assess causal relationships between MHR and FAR levels and the development and/or progression of carotid atherosclerosis. Third, we did not investigate other inflammatory markers and whether carotid lesions are stable or unstable. Fourth, we did not include symptomatic patients. Lastly, this study was not designed to report on long-term clinical outcomes.

\section{CONCLUSION}

Our results suggested that the ability of pre-angiographic MHR level to predict a clinically significant CAS was superior to that of FAR and hsCRP and could help us to early detect patients with asymptomatic CAS at high risk. Therefore, patients with asymptomatic CAS and high levels of MHR may require a close medical follow-up and an intensive treatment of risk factors. Large-scale clinical studies are needed to prove our findings.

\section{Conflict of Interest}

None.

\section{Source of Funding}

None.

\section{Author's Contribution}

Mustafa Yurtdaş: data curation, formal analysis, investigation methodology, project administration, resources, software, supervision, validation, writing of the original draft, review, and editing.

Yalin Tolga Yaylali: Formal analysis, Investigation, methodology, supervision, validation, visualization, writing of the original draft, review, and editing.

Mahmut Özdemir: Formal analysis, Investigation methodology, software, supervision, validation, visualization. 


\section{RESUMO}

OBJETIVO: Recentemente, a contagem de monócitos para a proporção HDL-C (MHR) e a relação fibrinogênio para albumina (FAR) emergiram como marcadores de inflamação em doenças ateroscleróticas. Nosso objetivo é investigar a relação da MHR e FAR com a gravidade da estenose da artéria carótida (CAS) em pacientes com doença assintomática da artéria carótida.

MÉTODOS: Este estudo retrospectivo incluiu 300 pacientes com CAS assintomática. MHR pré-angiográfica, FAR e proteína C reativa de alta sensibilidade (hsCRP) foram medidas. A angiografia carotídea foi realizada em pacientes com estenose $\geq 50 \%$ na ultrassonografia carotídea. Os pacientes foram primeiramente divididos em dois grupos com base no grau de CAS e depois nos tercis (T) da MHR.

RESULTADOS: Noventa e seis pacientes apresentaram um CAS clinicamente insignificante (<50\%) (grupo 1) e 204 pacientes apresentaram CAS clinicamente significativo ( $\geq 50 \%$ ) (grupo 2). O grupo 2 apresentou MHR, FAR e hsCRP superior ao grupo 1. Pacientes em T3 apresentaram maior MHR, FAR e hsCRP do que em T1 e T2. MHR, FAR e hsCRP foram correlacionados entre si ( $p<0,001$, para todos). MHR, FAR e hsCRP foram preditores independentes de CAS significativa. MHR predisse melhor uma CAS significativa que FAR e hsCRP $(p<0,05)$.

CONCLUSÕES: A MHR pré-angiográfica pode ser um melhor preditor que a FAR e a hSCRP na identificação de estenose carotídea clinicamente significativa em pacientes com CAS assintomática. Pacientes com CAS assintomática e alto nível de MHR devem ser acompanhados de perto para supervisionar o controle dos fatores de risco e intensificar o tratamento.

PALAVRAS-CHAVE: Inflamação. Estenose das carótidas. Monócitos. HDL-Colesterol. Fibrinogênio. Albuminas. Angiografia.

\section{REFERENCES}

1. Flaherty ML, Kissela B, Khoury JC, Alwell K, Moomaw C), Woo D, et al. Carotid artery stenosis as a cause of stroke. Neuroepidemiology. 2013;40(1):36-41.

2. Puz P, Lasek-Bal A, Ziaja D, Kazibutowska Z, Ziaja K. Inflammatory markers in patients with internal carotid artery stenosis. Arch Med Sci. 2013;9(2):254-60.

3. Ammirati E, Moroni F, Norata GD, Magnoni M, Camici PG. Markers of inflammation associated with plaque progression and instability in patients with carotid atherosclerosis. Mediators Inflamm. 2015;2015:718329.

4. van Dijk AC, Donkel SI, Zadi T, Sonneveld MAH, Schreuder FHBM, Chohan MF, et al. Association between fibrinogen and fibrinogen $\gamma$ ' and atherosclerotic plaque morphology and composition in symptomatic carotid artery stenosis: Plaque-At-RISK study. Thromb Res. 2019;177:130-5.

5. Ganjali S, Gotto AM Jr, Ruscica M, Atkin SL, Butler AE, Banach M, et al. Monocyte-to-HDL-cholesterol ratio as a prognostic marker in cardiovascular diseases. J Cell Physiol. 2018;233(12):9237-46.

6. Grosse GM, Schulz-Schaeffer WJ, Teebken OE, Schuppner R, Dirks M, Worthmann $\mathrm{H}$, et al. Monocyte subsets and related chemokines in carotid artery stenosis and Ischemic stroke. Int | Mol Sci. 2016;17(4):433.

7. Reina SA, Llabre MM, Allison MA, Wilkins |T, Mendez AJ, Arnan MK, et al. HDL cholesterol and stroke risk: the Multi-Ethnic Study of Atherosclerosis. Atherosclerosis. 2015;243(1):314-9.

8. Wang HY, Shi WR, Yi X, Zhou YP, Wang ZQ, Sun YX. Assessing the performance of monocyte to high-density lipoprotein ratio for predicting ischemic stroke: insights from a population-based Chinese cohort. Lipids Health Dis. 2019;18(1):127.

9. Paar M, Rossmann C, Nusshold C, Wagner T, Schlagenhauf A, Leschnik B, et al. Anticoagulant action of low, physiologic, and high albumin levels in whole blood. PLoS One. 2017;12(8):e0182997.

10. Joles JA, Willekes-Koolschijn N, Koomans HA. Hypoalbuminemia causes high blood viscosity by increasing red cell lysophosphatidylcholine. Kidney Int. 1997:52(3):761-70.

11. Sapmaz I, Saba T, Haberal C, Toktamis A, Cakmak M, Cicek D. Fibrinogen-albumin ratio: an intriguing relationship for assessing thrombosis risk and suspicious effect on blood viscosity. Int Cardiovasc Res ). 2011;5(4):153-4.

12. He D, Jiao Y, Yu T, Song J, Wen Z, Wu J, et al. Prognostic value of fibrinogen-to-albumin ratio in predicting 1-year clinical progression in patients with non-ST elevation acute coronary syndrome undergoing percutaneous coronary intervention. Exp Ther Med. 2019;18(4):2972-8.

13. Ya G, Qiu Z, Tianrong P. Relation of monocyte/high-density lipoprotein cholesterol ratio with coronary artery disease in type 2 diabetes mellitus. Clin Lab. 2018;64(6):901-6.

14. Vahit $D, A$, boga $M K$, Samet $Y$, Hüseyin E. Assessment of monocyte to high density lipoprotein cholesterol ratio and lymphocyte-to-monocyte ratio in patients with metabolic syndrome. Biomark Med. 2017;11(7):535-40.

15. Yilmaz S, Akboga M, Sen F, Balcı KG, Aras D, Temizhan A, et al. Usefulness of the monocyte-to-high-density lipoprotein cholesterol ratio to predict bare metal stent restenosis. Biomark Med. 2016;10(9):959-66.

16. Cetin MS, Ozcan Cetin EH, Kalender E, Aydin S, Topaloglu S, Kisacik HL, et al. Monocyte to HDL cholesterol ratio predicts coronary artery disease severity and future major cardiovascular adverse events in acute coronary syndrome. Heart Lung Circ. 2016;25(11):1077-86.

17. Karahan $\mathrm{O}$, Acet $H$, Ertas F, Tezcan $O$, Çalişkan A, Demir M, et al. The relationship between fibrinogen to albumin ratio and severity of coronary artery disease in patients with STEMI. Am J Emerg Med. 2016;34(6):1037-42.

18. Seo J, Kim GS, Lee HY, Byun YS, Jung IH, Rhee KJ, et al. Prevalence and clinical outcomes of asymptomatic carotid artery stenosis in patients undergoing concurrent coronary and carotid angiography. Yonsei Med ). 2019;60(6):542-6.

19. Djoussé L, Rothman KJ, Cupples LA, Arnett DK, Ellison RC; NHLBI Family Heart Study. Relation between serum albumin and carotid atherosclerosis: the NHLBI Family Heart Study. Stroke. 2003;34(1):53-7.

20. Zoccali C, Benedetto FA, Mallamaci F, Tripepi G, Fermo I, Focà A, et al. Inflammation is associated with carotid atherosclerosis in dialysis patients. Creed Investigators. Cardiovascular Risk Extended Evaluation in Dialysis Patients. J Hypertens. 2000;18(9):1207-13. 